\title{
Temporal Variations in Concentrations of Ozone, Nitrogen Dioxide, and Carbon Monoxide at Osijek, Croatia
}

\author{
Elvira Kovač-Andrić, Tatjana Radanović, Iva Topalović, \\ Berislav Marković, and Nikola Sakač \\ Department of Chemistry, University of Josip Juraj Strossmayer, Cara Hadrijana 8/A, 31000 Osijek, Croatia \\ Correspondence should be addressed to Elvira Kovač-Andrić; eakovac@kemija.unios.hr
}

Received 6 September 2013; Revised 19 November 2013; Accepted 21 November 2013

Academic Editor: Harry D. Kambezidis

Copyright (C) 2013 Elvira Kovač-Andrić et al. This is an open access article distributed under the Creative Commons Attribution License, which permits unrestricted use, distribution, and reproduction in any medium, provided the original work is properly cited.

\begin{abstract}
The purpose of this study was to investigate the ozone, carbon monoxide, and nitrogen dioxide variations and their correlation with meteorological parameters in Osijek (Eastern Croatia) during the summer seasons of 2002, 2007, and 2012. The measured data are discussed in relation to the EU guidelines (Directive 2002/3/EC, Directive 2008/50/EC). In order to characterize ambient air with respect to ozone photochemical pollution we calculated three photochemical pollution indicators. These indicators may also be a valid measure for harmful effects on living organisms. The influence of local meteorological parameters on the measured concentrations of ozone, carbon monoxide, and nitrogen dioxide was also investigated. We have attempted to establish correlations between measured pollutant concentrations and meteorological parameters using the technique of multivariate principal component analysis (PCA).
\end{abstract}

\section{Introduction}

Air pollution is a common theme for the past decades because of it is growing source of general pollution and the most common source in urban areas being vehicle exhaust. The main pollutants from diesel fuel vehicles include carbon monoxide (CO) and nitrogen dioxide $\left(\mathrm{NO}_{2}\right)$ from which secondary pollutant ozone $\left(\mathrm{O}_{3}\right)$ is formed [1]. For a long time, ozone was fairly constant trace constituent of the air, but, in recent years, its concentration in the surface layer of the atmosphere shows a steady increase and at the present time it is greater than ever. Its volume fraction during the preindustrial period increased 2 to 4.5 times and it is still rising [2].

In urban areas or polluted atmosphere various reactions are carried out in which the formation of $\mathrm{O}_{3}$ depends on the ratio of nitrogen oxides $\left(\mathrm{NO}_{x}\right)$, while the effect of $\mathrm{CO}$ cycles is such that it slowly oxidizes nitrogen monoxide (NO) to nitrogen dioxide $\left(\mathrm{NO}_{2}\right)$ and thus indirectly affects the concentration of ozone. Carbon monoxide molecules are entering the cycle of oxidation, and nitrogen monoxide $(\mathrm{NO})$ is oxidized to nitrogen dioxide $\left(\mathrm{NO}_{2}\right)$. Nitrogen oxides originate mainly from anthropogenic sources, and increased production of ozone in the lower layer is associated with the cycles of photochemical reactions involving volatile organic compounds (VOCs) [3]. Anthropogenic emissions of VOCs and $\mathrm{NO}_{x}$ induce changes in the natural sources of tropospheric ozone. If the mixture of $\mathrm{NO}_{x}$ and VOCs is irradiated with the visible light, ozone will be generated in the reaction vessel until all the VOCs are spent. The same process is taking place in the air to form large amounts of ozone by solar radiation in the presence of $\mathrm{NO}_{x}$ and VOCs. The hydroxyl radicals, $\mathrm{CO}$ and $\mathrm{NO}$, participating in the photochemical production of ozone, give about $1 \mathrm{ppb}$ of ozone per day in the high troposphere, from where it is rapidly moving to the lower troposphere [4]. Global emission of $\mathrm{NO}_{x}$ is mainly of anthropogenic origin and caused by fossil fuel burning, the largest part of which being from automobile exhaust gases. The reduction of the $\mathrm{O}_{3}$ concentration is observed after introduction of automotive catalysts in the last decade of the 20th century [5-7]. For a long time it was thought that the transport of ozone from the stratosphere is a dominant source of its presence in the troposphere, but today it is recognized that ozone in the troposphere is mainly a product of controlled decomposition within the troposphere itself. In a series of photochemical 
reactions that generate ozone, hydroxyl radical leads to its formation, but at the same time they react with ozone destroying it. Which reaction will be predominating depends on the local concentration ratio of $\mathrm{NO} / \mathrm{O}_{3}$. Overall, photochemical destruction of ozone will occur at higher concentrations of NO. To assess how much ozone is formed one has to start from the degradation rate of carbon monoxide in the reaction with the hydroxyl radical [5]. The photochemical decomposition of ozone occurs during the day, depending on the proportion of relative humidity, and it is most effective in the surface layer of the atmosphere. It is estimated that about $75 \%$ of the photochemical ozone depletion occurs in the described way. The control of air quality issues includes the impact of ozone on vegetation [8], animals [9], and humans $[10,11]$. Control of the air pollution is based on the ecological and economic principles and requires an understanding of the interaction between the atmosphere and biosphere.

In this paper, we present different analysis patterns in behavior of the leading species in photochemically polluted air $\left(\mathrm{CO}, \mathrm{NO}_{2}\right.$, and $\left.\mathrm{O}_{3}\right)$ in order to find their dependence on anthropogenic activity and meteorological conditions. The first ozone monitoring in ambient air in Eastern Slavonia was reported for the growth season in 2002 when there were no significant photochemical pollution problems [12]. During summer months in many urban and rural areas the excessive concentrations of oxidants are formed in the atmosphere so we are comparing measurements from June to September of 2002, 2007, and 2012 in Osijek (Figure 1). There is no available data for $\mathrm{CO}$ and $\mathrm{NO}_{2}$ concentrations in 2002, but we have collected them for years 2007 and 2012. For the first time these data are correlated with those for ozone concentrations and meteorological parameters. Another approach for the assessment of ambient air quality is by calculating photochemical pollution indicators during the summer seasons of 2002, 2007, and $2012[13,14]$. These indicators include, as a basic parameter, the average of the daily maximum to minimum ratio calculated from hourly ozone concentrations measured over a period of time. Furthermore, we have attempted to establish correlations between measured pollutant concentrations and meteorological parameters using the technique of multivariate principal component analysis (PCA).

\section{Experimental}

Ozone volume fractions have been measured and analyzed in the city of Osijek. Monitoring site was located at the northern boundary of city, close to the river Drava and approximately $15 \mathrm{~m}$ above the ground. Osijek is the largest urban centre in Eastern Croatia located at $45.32^{\circ} \mathrm{N}, 18.44^{\circ} \mathrm{E}$ (with a population of aprox. 130,000) without significant industry and, therefore, precursor emission is mainly due to traffic. The measurements took place during summer seasons (June through September) of 2002, 2007, and 2012, using a commercial instrument Ansyco O341 M based on UV absorption photometry. The instrument was regularly checked and calibrated. The data have been recorded every $3 \mathrm{~min}$ and stored in data logger for further processing on a computer. Data analysis is commonly based on hourly average; therefore, the data were transferred to Excel Macro tables.

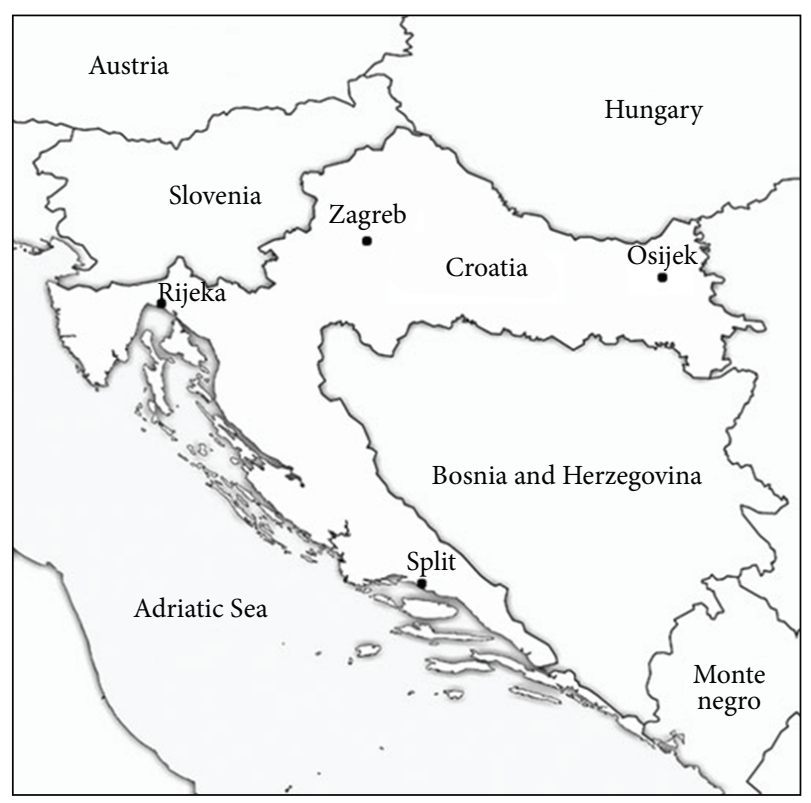

FIgURE 1: Location of Osijek, Croatia.

Air pollution quality data were obtained from the Ministry of Environmental and Nature Protection of Croatia which is monitoring the $\mathrm{NO}_{2}$ and $\mathrm{CO}$ concentrations (monitoring station cca. $100 \mathrm{~m}$ to the east of the ozone measurement site). Unfortunately, the data for $\mathrm{NO}_{2}$ and $\mathrm{CO}$ are not available for the year of 2002 but, however, there are measurements for June through September of 2007 and 2012.

Meteorological data were obtained from the Meteorological and Hydrological Service of Croatia. They have monitoring site for meteorological parameters at Klisa (airport cca. $20 \mathrm{~km}$ to the southeast of our monitoring site).

\section{Results and Discussion}

The data were converted to hourly average ozone volume fractions and average daily values were calculated for the measured periods in 2002, 2007, and 2012.

Air pollution is usually defined by indices to assess the quality of air on the basis of the measured values in a specific time and place and to inform the public whether the current ambient air can be regarded as "good" or "unhealthy" $[15,16]$. To characterize ambient air with respect to photochemical pollution, we also calculated two photochemical pollution indicators for measured periods. These two parameters are related to the ozone volume fractions when hourly averages of $60 \mathrm{ppb}$, as the limit value for air quality, are exceeded [1719]. One $\left(P_{1}\right)$ gives a total volume fraction that is over the limit for the entire period, and the second $\left(P_{2}\right)$ is the total number of hours in which the limit of $60 \mathrm{ppb}$ was exceeded. If $P_{1}$ is higher than 7 , measurement sites are considered clean from the photochemical pollution. The calculation of $P_{2}$ gives a simple option for grouping the data into three classes: clean $\left(P_{2}<10\right)$, medium clean $\left(10<P_{2}<100\right)$, and polluted $\left(P_{2}>\right.$ $100)[13,14]$. The photochemical pollution indicators for the period of June-September were calculated from the formulas 
$P_{1}=R M / A$ and $P_{2}=R\left(1+7 D / N_{d}\right)$, where $R$ is the average maximum to minimum ratio of hourly ozone data, $M$ is the average maximum value, $A$ is the average of hourly mean values, $D$ is the number of days for which ozone volume fractions have exceeded the limit of $60 \mathrm{ppb}$, and $N_{d}$ is the number of monitoring days per monitoring period, in our case 101 days. The geometrical mean of the previous two indicators gives third indicator [14]. Furthermore, $P_{3}$ includes both corrections and accounts for situations when the previous two indicators differ significantly $\left(P_{3}=\sqrt{P_{1} \cdot P_{2}}\right)$.

These three indicators should have a greater value when $R$ is high. Considering that the $R$ explains the difference between the daily maximum and minimum and thus indirectly the daily ozone turnover, these indicators may also draw attention for harmful effects on living organisms.

The four stations of the European network (Cooperative Programme for Monitoring and Evaluation of Long-Range Transmission of Air Pollutants in Europe, EMEP) were selected to compare pollution indicators with the monitoring site in Osijek. Three stations of them are located in rural area (K-Puszta, Krvavec, and Illmitz) and one station is located near urban area (Montelibretti). The full geographical coordinates can be found on the web (www.nilu.no/projects/ccc/ network.html). They are listed in Table 1 together with their data about pollution indicators.

When comparing the results at the Osijek with other stations, in the Osijek indicator values are higher than those of the three rural stations but significantly less than those of the Montelibretti.

Given the calculated values of $P_{1}$ Osijek belongs to the medium clean due to photochemical air pollution (Table 1) and these values are relatively constant. It is obvious that the values of $P_{3}$ indicator increase every five years. According to $P_{2}$ values, Osijek was medium clean in 2002, while, during year 2007 and 2012, the value of this index increased for more than 3 times, and in those years Osijek can be classified as polluted.

The average diurnal variations of ozone concentration for the measured periods are shown in Figure 2. Even though variability between years was observed, generally, in the magnitude of the amplitude, there is almost no change in the diurnal distribution. It is evident that every five years ozone values are rising. The distribution of values resembles a typical behavior for an urban site. The daily maximum values were measured in the afternoon hours indicating that the source of primary pollutants is located close to the monitoring site $[12,20]$. On the other hand, these values are low for an urban site indicating that the air is well mixed with that of the surrounding region. Indeed, the city of Osijek lies in a plain allowing winds from all directions and the wind rose closely resemble a circle.

By calculating all the 8-hourly moving average concentrations of ozone, it was found that the threshold value of $120 \mu \mathrm{g} / \mathrm{m}^{3}$ (60 ppb) was not exceeded during 2002, while in 2007 this value was exceeded during 21 days for a total of 181 hours. Throughout all the measurements in the year of 2012 the 8-hourly moving average concentrations of ozone were found to exceed the value of $120 \mu \mathrm{g} / \mathrm{m}^{3}$ in 26 days for a total of 288 hours. According to the Croatian Directive on Ozone
TABle 1: Photochemical pollution indicators $P_{1}, P_{2}$, and $P_{3}$ for summer seasons.

\begin{tabular}{lccccc}
\hline When & Where & $P_{1}$ & $P_{2}$ & $P_{3}$ & Reference \\
\hline $1997-2003$ & K-Puszta, Hungary & 6.1 & 5.4 & 5.7 & \\
$1997-2003$ & Krvavec, Slovenia & 1.8 & 2.5 & 2.1 & \\
$1997-2003$ & Illmitz, Austria & 4.7 & 5.1 & 4.9 & {$[13]$} \\
$1997-2003$ & Montelibretti, Italy & 97 & 220 & 146.1 & \\
2002 & Osijek, Croatia & 28.4 & 30.5 & 29.4 & \\
2007 & Osijek, Croatia & 24.7 & 100.4 & 49.8 & This work \\
2012 & Osijek, Croatia & 28.1 & 110.9 & 55.8 & \\
\hline
\end{tabular}

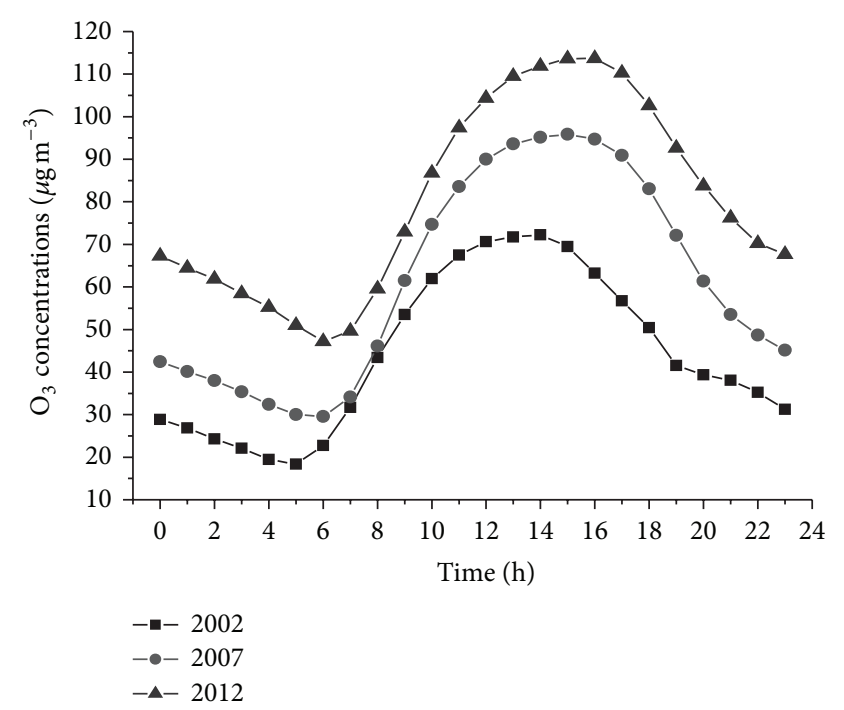

FIGURE 2: Average diurnal distribution of $\mathrm{O}_{3}$ volume fractions for the measured periods.

[21] and Guidelines of the European Union, ozone pollution in ambient air is allowed to exceed this value $\left(120 \mu \mathrm{g} / \mathrm{m}^{3}\right)$ for 25 days during one year.

Furthermore, we have analyzed measured concentrations for carbon monoxide and nitrogen dioxide during 2007 and 2012.

A comparison of the average diurnal ozone profiles for $\mathrm{CO}$ and $\mathrm{NO}_{2}$ concentrations shows that maximum values for these pollutants precede and follow the maximum concentration of $\mathrm{O}_{3}$ (Figure 3). The distribution of values for these pollutants is different than that for diurnal ozone [22]. The daily maximum values for $\mathrm{CO}$ and $\mathrm{NO}_{2}$ were measured during the morning and nightly hours. This pattern is representative of urban atmosphere in this climatic region and it is in correspondence with increased morning (06:00-08:00) and nightly (20:00-22:00) traffic densities [23]. The observed decrease in concentrations of $\mathrm{CO}$ and $\mathrm{NO}_{2}$ between 2007 and 2012 is expected because of the increase in the concentration of ozone. The main sources of $\mathrm{CO}$ and $\mathrm{NO}_{2}$ are man-made, and for the most part are coming from automobile exhaust gases $[24,25]$. Their emission depends on the age, maintenance, and vehicle technology.

By calculating all the average concentrations for the year of 2007 and 2012, it is clear that limit values of these pollutants were not exceeded (limit value for CO is $10 \mathrm{mg} / \mathrm{m}^{3}$ - as given 


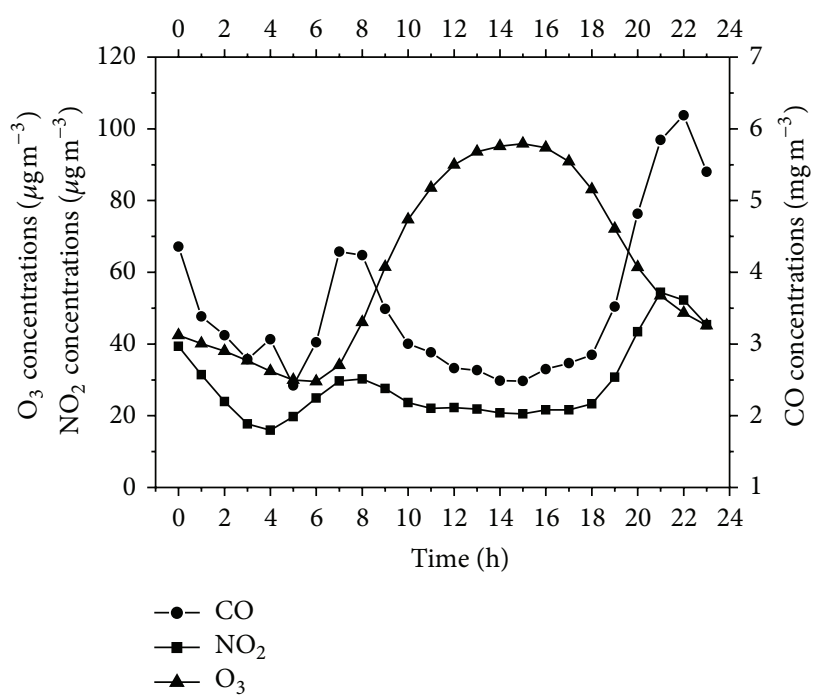

(a)

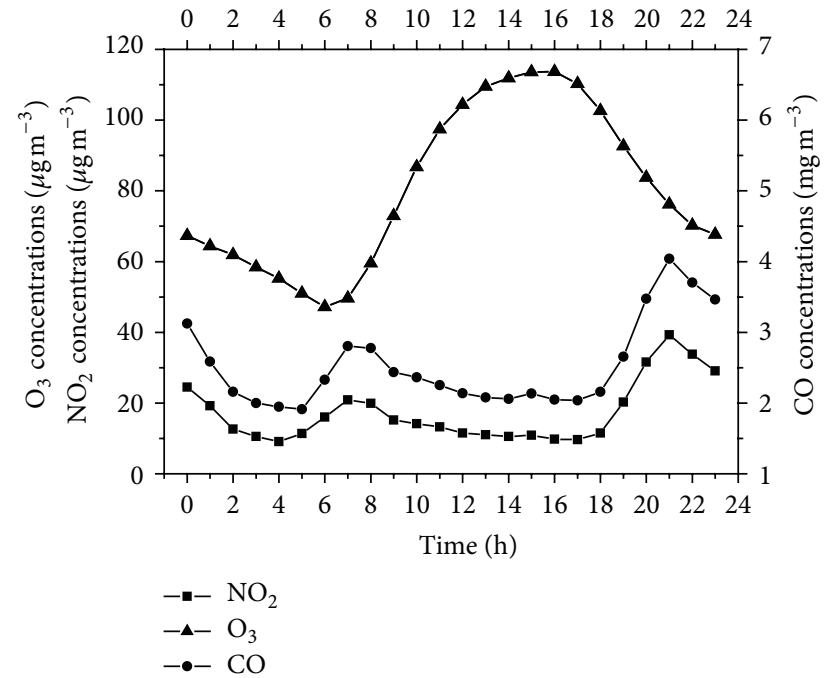

(b)

Figure 3: Average diurnal variations of $\mathrm{O}_{3}, \mathrm{CO}$, and $\mathrm{NO}_{2}$ for the measured periods 2007 (a) and 2012 (b).

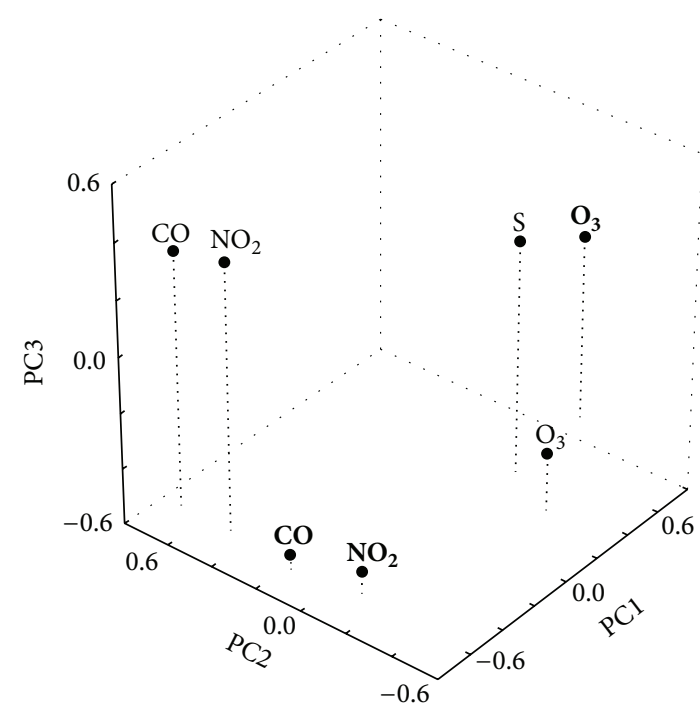

(a)

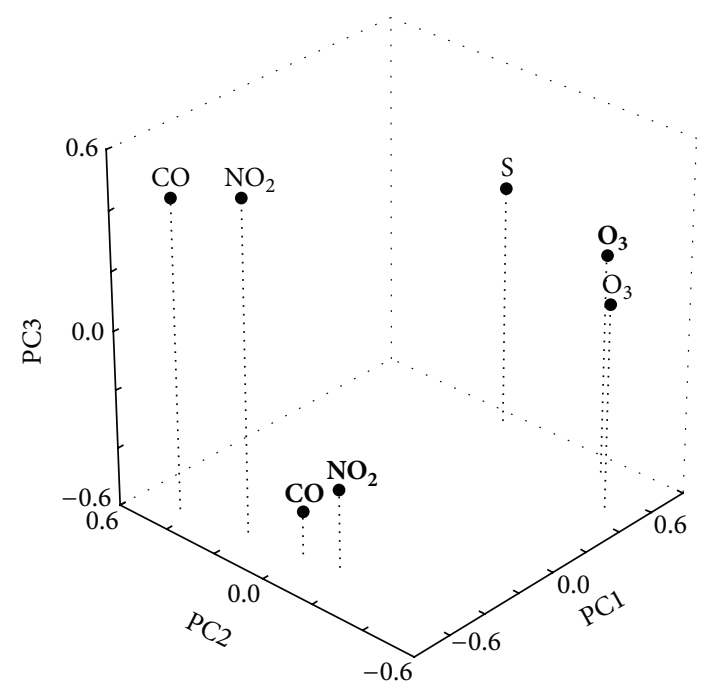

(b)

FIGURE 4: 3D plots of score and loadings (night concentrations appear in bold) for the measured periods 2007 (a) and 2012 (b).

by $2000 / 69 /$ EC Directive for the maximum daily 8 -hour mean concentration-and for $\mathrm{NO}_{2} 200 \mu \mathrm{g} / \mathrm{m}^{3}$-as given by $2008 / 50 /$ EU Directive the maximum daily 1-hour mean concentration - not to be exceeded more than 18 times in a calendar year) $[18,19]$.

Furthermore, we divided these concentrations into two groups: day values (solar radiation, $S>0 \mathrm{Wm}^{-2}$, between 05:00 and 20:00) and night values (20:00-05:00). During the measuring campaign, local time corresponded to Central European Time (CET). Obtained daily and night concentrations and solar radiation data were subjected to the factor analysis in order to define variables which will describe their interdependence. Factors were based on principal component analysis (PCA) followed by varimax rotation methods. Three significant factors were extracted for 2007th and 2012th and the total variance amounted $83.9 \%$ and $84.5 \%$, respectively. In either case similar results were obtained (Figure 4). The first factor describes the influence of solar radiation on ozone formation. The second factor separates daily concentrations $\mathrm{CO}$ and $\mathrm{NO}_{2}$ from their nightly concentration (third factor) and indicates their common origin. This developed model also indicates that the concentrations $\mathrm{NO}_{2}$ and $\mathrm{CO}$ were strongly negatively correlated with $\mathrm{O}_{3}$. Higher concentrations $\mathrm{NO}_{2}$ and $\mathrm{CO}$ are associated with lower ozone concentrations and back, due to photochemical reactions.

We calculated Pearson's correlation coefficients between pollutant concentrations and meteorological variables: temperature $(t)$, relative humidity $(\mathrm{rh})$, atmospheric pressure $(p)$, 
TABLE 2: Pearsons, correlation coefficients between $\mathrm{O}_{3}, \mathrm{NO}_{2}$, and $\mathrm{CO}$ daily average concentrations and meteorological parameters for the measured periods in 2007 and 2012 (statistically significant values with $P<0.05$ are present in bold).

\begin{tabular}{|c|c|c|c|c|c|c|c|c|c|}
\hline \multicolumn{10}{|c|}{2007} \\
\hline & $\mathrm{O}_{3}$ & $\mathrm{NO}_{2}$ & $\mathrm{CO}$ & $t$ & rh & $p$ & vis & $S$ & ws \\
\hline $\mathrm{O}_{3}$ & 1.000 & 0.247 & -0.126 & 0.787 & -0.709 & -0.281 & 0.253 & 0.561 & -0.211 \\
\hline $\mathrm{NO}_{2}$ & & 1.000 & 0.805 & 0.333 & -0.487 & 0.095 & -0.132 & 0.198 & -0.459 \\
\hline $\mathrm{CO}$ & & & 1.000 & -0.009 & -0.177 & 0.224 & -0.226 & -0.031 & -0.179 \\
\hline$t$ & & & & 1.000 & -0.652 & -0.412 & 0.262 & 0.643 & -0.281 \\
\hline rh & & & & & 1.000 & -0.086 & -0.168 & -0.437 & 0.364 \\
\hline$p$ & & & & & & 1.000 & -0.266 & -0.324 & -0.159 \\
\hline vis & & & & & & & 1.000 & 0.466 & 0.226 \\
\hline$S$ & & & & & & & & 1.000 & -0.051 \\
\hline ws & & & & & & & & & 1.000 \\
\hline \multicolumn{10}{|c|}{2012} \\
\hline $\mathrm{O}_{3}$ & 1.000 & -0.053 & -0.169 & 0.466 & -0.439 & -0.170 & 0.480 & 0.411 & 0.020 \\
\hline $\mathrm{NO}_{2}$ & & 1.000 & 0.901 & 0.363 & -0.214 & -0.225 & -0.028 & 0.201 & -0.404 \\
\hline $\mathrm{CO}$ & & & 1.000 & 0.247 & -0.080 & -0.165 & -0.138 & 0.076 & -0.318 \\
\hline$t$ & & & & 1.000 & -0.489 & -0.467 & 0.461 & 0.743 & -0.367 \\
\hline rh & & & & & 1.000 & -0.032 & -0.408 & -0.422 & 0.362 \\
\hline$p$ & & & & & & 1.000 & -0.180 & -0.369 & 0.140 \\
\hline vis & & & & & & & 1.000 & 0.731 & 0.014 \\
\hline$S$ & & & & & & & & 1.000 & -0.157 \\
\hline ws & & & & & & & & & 1.000 \\
\hline
\end{tabular}

visibility (vis), solar radiation (S), and wind speed (ws) for a measured period of 2007 and 2012 (Table 2).

Calculated correlation coefficients show the existence of significant correlation between $\mathrm{O}_{3}$ and temperature, solar radiation, and visibility, which was expected due to the photochemical reactions. High levels of $\mathrm{O}_{3}$ during the measurements are associated with favorable meteorology and the intense precursor emission. Also, concentration of $\mathrm{O}_{3}$ significantly negatively correlates with relative humidity, because lower humidity usually corresponds to higher temperatures, higher solar radiation, and higher $\mathrm{O}_{3}$ formation rates $[23,26]$.

Correlations between $\mathrm{O}_{3}, \mathrm{CO}$, and $\mathrm{NO}_{2}$ are low and considered not to be significant. High correlation coefficients were achieved between $\mathrm{CO}$ and $\mathrm{NO}_{2}$ and that was expected because $\mathrm{CO}$ influences the oxidation of $\mathrm{NO}$ to $\mathrm{NO}_{2}$. Furthermore, $\mathrm{CO}$ does not significantly correlate with measured meteorological parameters, while relative humidity and wind speed are negatively correlated with $\mathrm{NO}_{2}$.

A good understanding of interdependence between meteorology and pollutant concentrations is necessary to evaluate the effects of one on the other. PCA has been successfully applied to identify the dominant relationships present within measured data [27]. PCA followed by varimax rotation yields the results that are given in Figure 5 for the loadings (i.e., biplot). It provides an overview of interrelationships between monitored meteorological parameters and collected air sample properties. The model developed for both the ozone and meteorological variables indicates that ozone strongly correlates with temperature, solar radiation, and visibility. Ozone concentrations are highly influenced by temperature and solar radiation time which reflects the importance of photochemistry in ozone formation. Furthermore, analysis of this data during summer showed that wind speed, relative humidity, and air pressure do not have effect on ozone formation. Higher relative humidity and wet weather are usually associated with lower ozone concentration due to reduction of photochemical activity, but the main factor that decreases ozone concentration is reduced solar radiation and lower temperature $[23,26]$. Once again it is shown that $\mathrm{CO}$ and $\mathrm{NO}_{2}$ strongly positively correlate with each other. It has been proven that PCA can be a useful and effective tool for researching voluminous sets of data such as ozone concentration and meteorological data. Its application helps to visualize dominant relationships that exist within measured data.

\section{Conclusion}

This study indicates that there are important relationships between changes in meteorological parameters and ozone level in boundary layer. During summer, the city of Osijek is under heavier traffic load which is shown by two photochemical pollution indicators which are the consequence of anthropogenic factors. Concentrations of $\mathrm{CO}$ and $\mathrm{NO}_{2}$ do not exceed the limits given by the EU Directive and Croatian laws, while ozone concentrations exceed these values. Results of calculating the correlation coefficients and PCA revealed underlying relationships between $\mathrm{O}_{3}$ concentrations and meteorological data and showed that ozone concentrations are associated with temperature, solar radiation, and visibility. Pollutants $\mathrm{CO}$ and $\mathrm{NO}_{2}$ significantly correlate with each other. Further and permanent studies are certainly needed in order to closely identify human effects on the levels of these pollutants in the boundary layer of the atmosphere. 


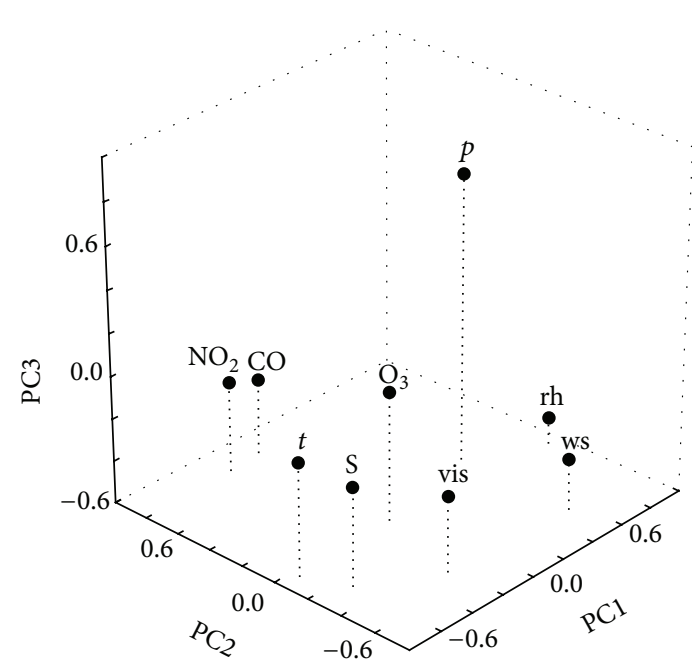

(a)

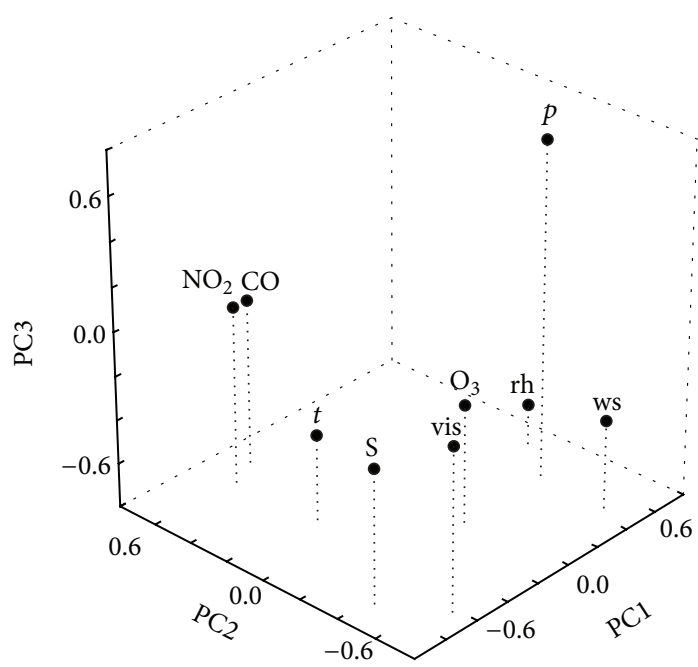

(b)

FIGURE 5: 3D plot of score and loadings (biplot) for the measured periods 2007 (a) and 2012 (b).

\section{Acknowledgments}

The authors gratefully acknowledge the financial support given to the project by the Croatian Ministry of Science, Education and Sports. The authors also thank the Ruđer Bošković Institute, the Meteorological and Hydrological Service of Croatia, and the Ministry of Environmental and Nature Protection.

\section{References}

[1] A. Charron and R. M. Harrison, "Primary particle formation from vehicle emissions during exhaust dilution in the roadside atmosphere," Atmospheric Environment, vol. 37, no. 29, pp. 4109-4119, 2003.

[2] R. Vingarzan, "A review of surface ozone background levels and trends," Atmospheric Environment, vol. 38, no. 21, pp. 3431-3442, 2004.

[3] S. E. Bauer and B. Langmann, "Analysis of a summer smog episode in the Berlin-Brandenburg region with a nested atmosphere-chemistry model," Atmospheric Chemistry and Physics, vol. 2, no. 4, pp. 259-270, 2002.

[4] P. O. Wennberg, T. F. Hanisco, L. Jaeglé et al., "Hydrogen radicals, nitrogen radicals, and the production of $\mathrm{O}_{3}$ in the upper troposphere," Science, vol. 279, no. 5347, pp. 49-53, 1998.

[5] J. H. Seinfeld and S. N. Pandis, Atmospheric Chemistry and Physics: From Air Pollution To Climate Change, John Wiley \& Sons, New York, NY, USA, 2nd edition, 2006.

[6] J. T. Houghton, Y. Ding, D. J. Griggs et al., "Climate change 2001: the scientific basic," IPPC, Cambridge University Press, Cambridge, UK, 2001.

[7] M. V. Toro, L. V. Cremades, and J. Calbó, "Relationship between VOC and $\mathrm{NO}_{x}$ emissions and chemical production of tropospheric ozone in the Aburrá Valley (Colombia)," Chemosphere, vol. 65, no. 5, pp. 881-888, 2006.

[8] M. R. Ashmore, "Assessing the future global impacts of ozone on vegetation," Plant, Cell and Environment, vol. 28, no. 8, pp. 949-964, 2005.
[9] A. N. Mikerov, X. Gan, T. M. Umstead et al., "Sex differences in the impact of ozone on survival and alveolar macrophage function of mice after Klebsiella pneumoniae infection," Respiratory Research, vol. 9, article 24, 2008.

[10] J. A. Patz, D. Campbell-Lendrum, T. Holloway, and J. A. Foley, "Impact of regional climate change on human health," Nature, vol. 438, no. 7066, pp. 310-317, 2005.

[11] M. Kampa and E. Castanas, "Human health effects of air pollution," Environmental Pollution, vol. 151, no. 2, pp. 362-367, 2008.

[12] E. Kovač and T. Cvitaš, "Boundary layer ozone in Osijek, Eastern Croatia," Geofizika, vol. 24, no. 2, pp. 117-122, 2007.

[13] E. Kovač-Andrić, G. Šorgo, N. Kezele, T. Cvitaš, and L. Klasinc, "Photochemical pollution indicators-an analysis of 12 European monitoring stations," Environmental Monitoring and Assessment, vol. 165, no. 1-4, pp. 577-583, 2010.

[14] L. Klasinc, T. Cvitaš, S. P. McGlynn, M. Hu, X. Tang, and Y. Zhangd, "Photochemical pollution indicators in the subtropics," Croatica Chemica Acta, vol. 84, no. 1, pp. 11-16, 2011.

[15] A. D. McNaught and A. Wilkinson, Compendium of Chemical Terminology: Iupac Recommendations, Blackwell Science, Oxford, UK, 2nd edition, 1997.

[16] X.-K. Wang and W.-Z. Lu, "Seasonal variation of air pollution index: Hong Kong case study," Chemosphere, vol. 63, no. 8, pp. 1261-1272, 2006.

[17] "Directive 2002/3/EC of the European Parliament and of the Council relating to ozone in ambient air," Official Journal of the European Communities L 67 LEX-FAOC039805, 2002.

[18] "Directive 2008/50/EC of the European Parliament and of the Council on ambient air quality and cleaner air forEurope," Official Journal of the European Union L 152 LEX-FAOC080016, 2008.

[19] "Directives 2000/69/EC of the European Parliament and of the Council of 18 November 2000 relating to limit values for benzene and carbon monoxide in ambient air," Official Journal of the European Union L 313 LEX-FAOC038310, 2000.

[20] S. J. Oltmans, A. S. Lefohn, J. M. Harris et al., "Long-term changes in tropospheric ozone," Atmospheric Environment, vol. 40, no. 17, pp. 3156-3173, 2006. 
[21] R. H. Vlada, "Directive on ozone in air," 130/11, Narodne Novine, Zagreb, Croatia, 2011 (Croatian).

[22] R. G. Derwent, P. G. Simmonds, S. Seuring, and C. Dimmer, "Observation and interpretation of the seasonal cycles in the surface concentrations of ozone and carbon monoxide at Mace Head, Ireland from 1990 to 1994," Atmospheric Environment, vol. 32, no. 2, pp. 145-157, 1998.

[23] V. Gvozdić, E. Kovač-Andrić, and J. Brana, "Influence of meteorological factors $\mathrm{NO}_{2}, \mathrm{SO}_{2}, \mathrm{CO}$ and $\mathrm{PM}_{10}$ on the concentration of $\mathrm{O}_{3}$ in the urban atmosphere of Eastern Croatia," Environmental Modeling and Assessment, vol. 16, no. 5, pp. 491-501, 2011.

[24] T. Yorifuji, I. Kawachi, M. Kaneda, S. Takao, S. Kashima, and H. Doi, "Diesel vehicle emission and death rates in Tokyo, Japan: a natural experiment," Science of the Total Environment, vol. 409, no. 19, pp. 3620-3627, 2011.

[25] K. S. Bradley, D. H. Stedman, and G. A. Bishop, "A global inventory of carbon monoxide emissions from motor vehicles," Chemosphere, vol. 1, no. 1-3, pp. 65-72, 1999.

[26] E. Kovač-Andrić, J. Brana, and V. Gvozdić, "Impact of meteorological factors on ozone concentrations modelled by time series analysis and multivariate statistical methods," Ecological Informatics, vol. 4, no. 2, pp. 117-122, 2009.

[27] M. Statheropoulos, N. Vassiliadis, and A. Pappa, "Principal component and canonical correlation analysis for examining air pollution and meteorological data," Atmospheric Environment, vol. 32, no. 6, pp. 1087-1095, 1998. 

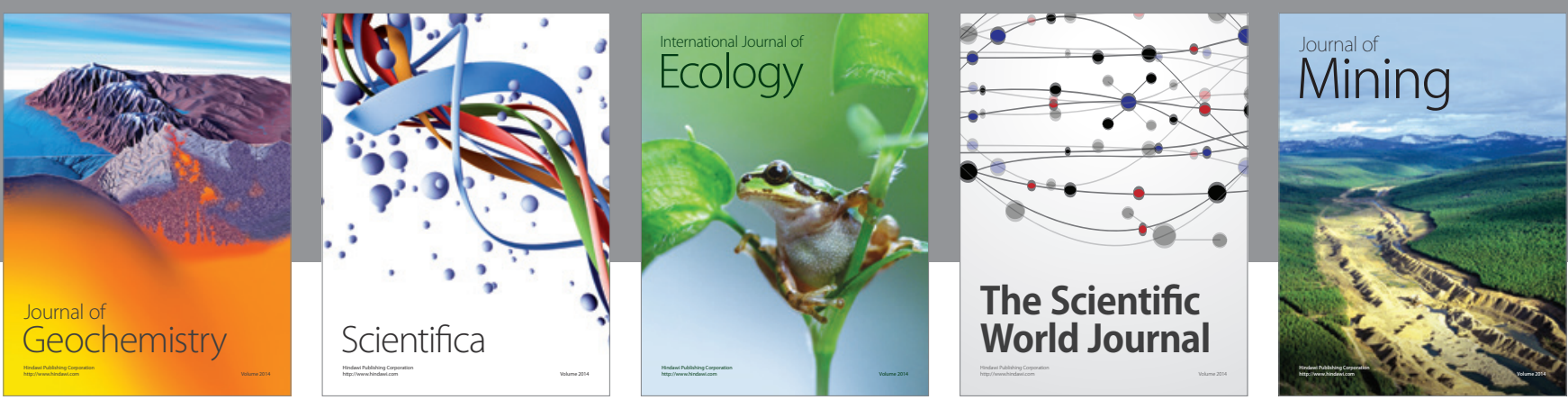

The Scientific World Journal
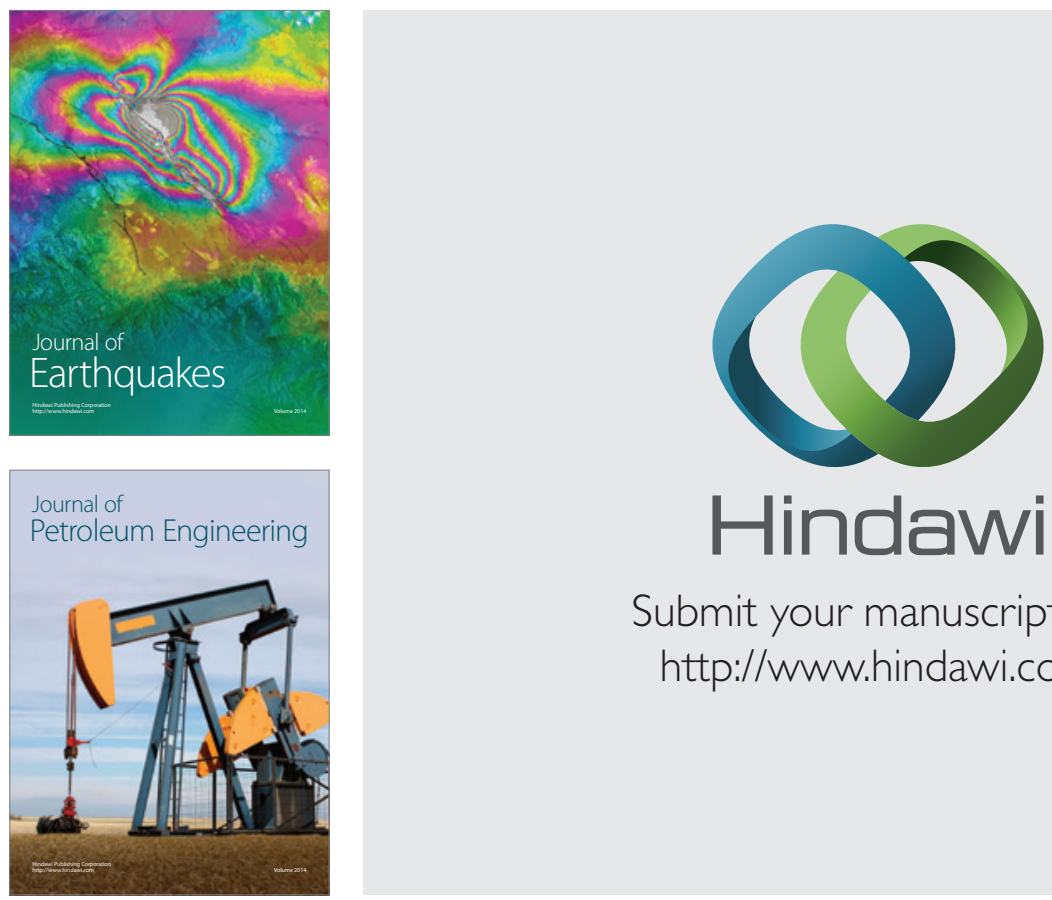

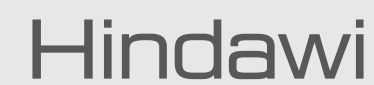

Submit your manuscripts at

http://www.hindawi.com
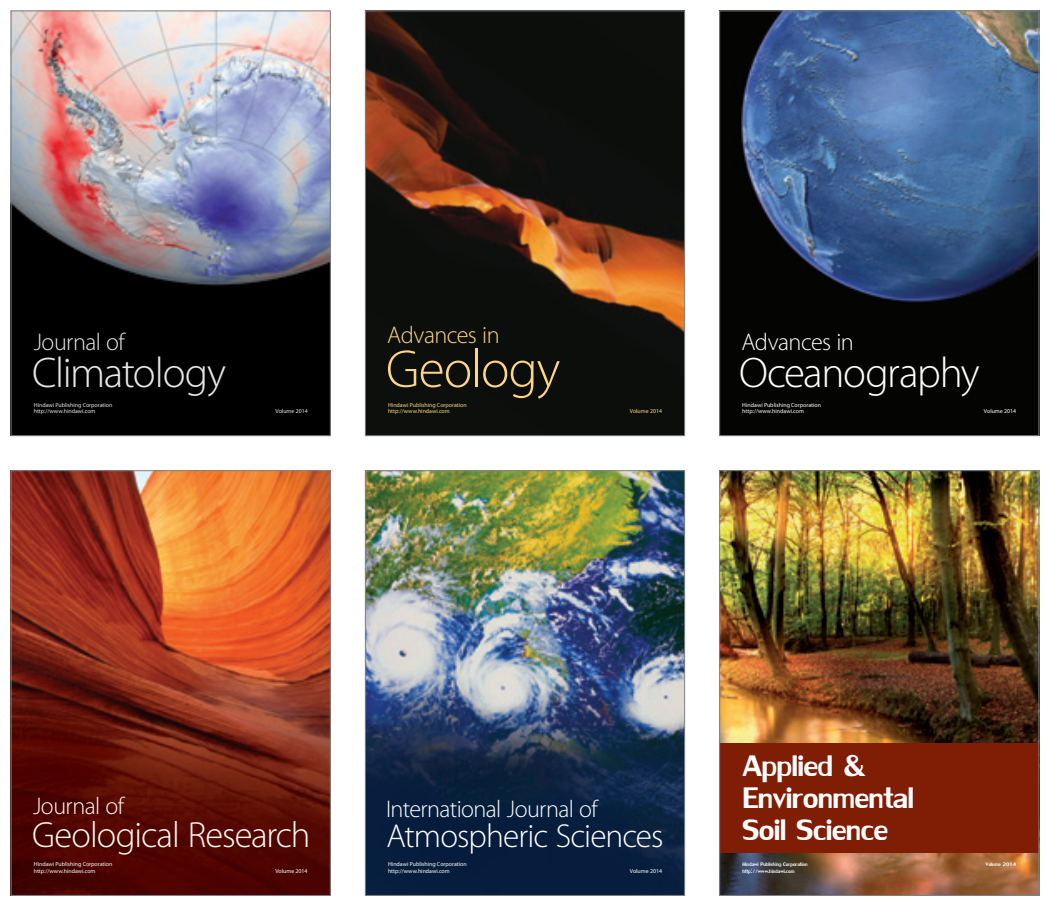
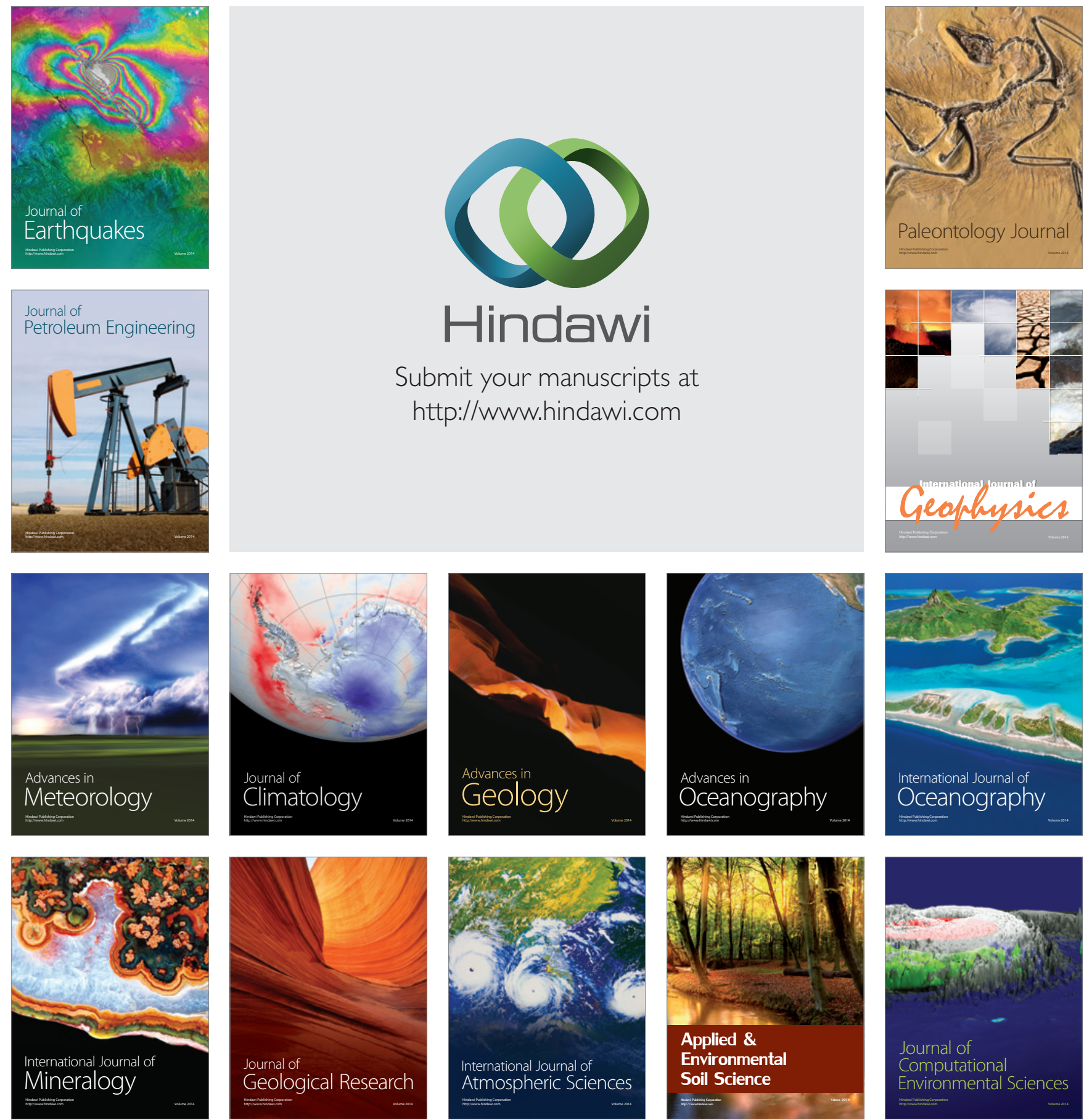